\title{
Stock Market's Reactions to Revelation of Tax Evasion: An Empirical Assessment
}

\author{
Andreas BrunharT ${ }^{a}$
}

JEL-Classification: C01, C22, G01, G14, G21

Keywords: Tax Evasion, Liechtenstein, Zumwinkel, Stock Price Volatility, Augmented GARCH, Event Study

\section{Introduction}

On February $14^{\text {th }} 2008$, German authorities arrested Klaus Zumwinkel, Chief Executive Officer and Chairman of Deutsche Post, in a very spectacular way at his home and in front of several TV-cameras: He was accused of tax evasion and subsequently resigned from office just a few days afterwards. Zumwinkel was convicted by the beginning of 2009. Along with about 600 other German tax evaders, Zumwinkel's tax fraud was unveiled by data provided by a whistle-blower named Heinrich Kieber, a Liechtenstein citizen, who is a former employee of LGT Bank. He sold the data to the German Intelligence Service (Bundesnachrichtendienst) for an estimated 5 Million Euros and also distributed the data to at least 13 other countries. Even though the identity of the whistle-blower was unveiled very soon, he could not be arrested yet and his domicile remains unknown despite the issue of an international arrest warrant in March 2008.

This affair, named "Zumwinkel-Affair" or "Liechtenstein Tax-Affair" by the press, led to stronger pressure on countries that were often called "tax-havens", especially Liechtenstein but as an indirect consequence later also on Luxemburg, Switzerland, Monaco and even Austria. The dramatic arrest of Zumwinkel ensured that the topic dominated the media for weeks (not only in Germany and Liechtenstein), while harsh statements by several politicians and political pressure

a Liechtenstein Institute. E-mail: andreas.brunhart@liechtensteininstitute.li.

The author would like to thank Robert Kunst (University of Vienna), Karl Schlag (University of Vienna), Martin Kocher (Ludwig-Maximilians-University Munich), Carsten-Henning Schlag (University of Liechtenstein), Kersten Kellermann (Konjunkturforschungsstelle Liechtenstein), Berno Büchel (University of Hamburg) and various participants of the "graduate and staff seminar" at the University of Vienna and also an anonymous referee for useful comments. 
by Germany played an important role ensuring that the issue of tax information exchange remained on the diplomatic agenda of both countries. Both international pressure and political debates within Liechtenstein, which had already been started before the data sale emerged, resulted in so far about 30 tax information exchange agreements within the last years. These new agreements led, among other things, to a still ongoing transformation process affecting all actors within Liechtenstein's financial sector. Combined with the already severe economic aftermath of the financial crisis, the affair was a strong challenge especially for the financial sector but also for Liechtenstein's entire economy.

Firstly, this contribution puts emphasis on the analysis and quantification of the Zumwinkel-Affair's impact on Liechtenstein's financial sector caused by the immediate consequences of the data theft (shock and irritation of markets and investors) but also by the affair's mid-term influences such as political pressure, capital outflows, transformation reforms and tax exchange agreements. Secondly, this particular affair is not only of interest itself, but more importantly a good example for the effects of a revelation of tax evasion on stock markets and investors' behaviour in general. The concrete question under investigation is (among others): Did the data theft, more precisely the arrest of Zumwinkel as an exactly timeable exogenous shock, affect average returns and volatility of related stock values? And if yes, what was the time frame of these effects?

The econometric analysis carried out implies an unconventional and augmented Generalized Autoregressive Conditional Heteroskedasticity (GARCH)model, named here as amalGARCH. ${ }^{1}$ It turns out that the amalGARCH-specification, which incorporates different combinations of the approaches by ENGLE (1982), WeIss (1984), and TAYLOR (1986) and BolLERSLEV (1986) to treat autoregressive conditional heteroskedasticity in a new framework, is preferable in this application for various reasons mentioned later on. ${ }^{2}$ Also, an event study is carried

1 Kunst (1997) investigates both specifications after ENGLE (1982) and the less well-known after Weiss (1984) considering stability conditions and empirical evidence. HaUSER and Kunst (1998) also employ the approach of WeIss (1984), although in the context of fractionally integrated models. See also Tsay (1987) for the discussion of related model classes.

2 Kollias, Papadamou, and Siriopoulos (2012) give a broad overview on studies on exogenous events, such as terrorist attacks, natural disasters or aviation crashes. Contributions that investigate the shock events' impact on mean and volatility of markets/economies in an ARCH-framework are for example Asteriou and Price (2001), Elyasiani, Mansur, and Odusami (2011) or HAMmOUdEH and YuAN (2008). They generally apply ordinary $\operatorname{GARCH}(p, q)$ models, which are amalGARCH$(p, q, 0)$ models in the notion introduced later on, augmented by dummies and other explanatory variables. Another example of an appropriate augmentation is given in Neusser and Burren (2010). They extend the ordinary conditional variance equation by 
out to analyse both the immediate short-term and the long-run effects of Zumwinkel's arrest on the stock value performances by breaking the sample and the sub-sample into an estimation and an event window.

As a reliable and frequently available proxy variable for the impact of the affair on Liechtenstein's financial sector, share prices of the companies within the financial sector are appropriate. The daily percentage returns of stock prices of the financial institutes whose shares are traded at the Swiss stock market ("Swiss Exchange") are used, namely of the banks "Verwaltungs- und Privatbank AG" and "Liechtensteinische Landesbank AG".

This contribution is structured as follows: Section 2 deals with the estimation of the augmented amalGARCH-models for the two stocks. To obtain an auxiliary classification, the applied models are systematically integrated into this new term "amalGARCH". Following a descriptive and visual investigation of the used data series, the econometric model setup is explained and the relevant results are presented (especially the impact of the Zumwinkel-Affair on the stock values' performance and risk), supplemented by various robustness checks. Section 2 also covers the event study and closes with a collection and interpretation of the main analytical findings from both the amalGARCH-regressions and the event study. In Section 3, the text concludes with some summarizing and complementary remarks.

\section{Zumwinkel Affair's Impact on Stock Prices and Risk}

The used data series are the stock prices of the banks "Verwaltungs- und Privatbank AG" (VPB) and "Liechtensteinische Landesbank AG" (LLB) which have their headquarters in Vaduz (Liechtenstein). Both stocks are traded at the Swiss Stock Exchange in Zürich and represent the only quoted companies from Liechtenstein. Also, the Swiss Market Index (SMI) is taken into account to capture the

deterministic regressors (time trends and time dummies). Expressed in the notation introduced later in this paper: They apply amalGARCH$(p, q, 0)$-approaches, augmented by deterministic regressors.

3 The LGT Bank, from which the stolen bank data was, is not quoted at the Swiss Exchange and therefore not investigated here. As to be seen later on, it is remarkable how affected the other two banks were by LGT's data theft. This also reflects the high level of following insecurity in the whole financial sector of Liechtenstein. A portrait of the mentioned banks, further facts to the economic impact of the financial crisis and the tax affair on Liechtenstein and additional examples describing the high international pressure are outlined in BRUNHART (2012, pp. 48-49). 
market fluctuations. The investigated time frame of the investigated variables series spans from 2006 (January $1^{\text {st }}$ ) to 2011 (January $4^{\text {th }}$ ), including about 1260 observations. ${ }^{4}$ Additional regressors, such as time dummies and other variables, are introduced later on.

\subsection{Visual and Descriptive Analysis of Data Series}

Inspecting the graphical movement of the employed time series (plotted in Figure 1) provides a few crucial insights. After the economic expansion phase that affected all sectors of the economy up to 2007 there is a clear downward tendency beginning to be evident from the end of 2007. There was a certain period of consolidation during 2008 before the dramatic worldwide downturn on the international stock markets took place, following the crash of Lehman Brothers in September 2008. The financial crisis, which had its origin already in the American sub-prime crisis, is clearly visible in the SMI with its extremum at the trough in March 2009. It is also easily visible that the SMI and the two banks' shares are strongly related and that all of them experienced a sharp decrease in their values after the peak in the middle of 2007 until the trough in March 2009.

The two arrows in Figure 1 mark the chosen time periods of the two time dummies for the Zumwinkel-Affair and the financial crisis, which are used in the regressions later on. To identify the time period where the financial crisis was at its maximum the SMI has been chosen as reference. The timing of the two dummies is motivated as follows: The time period of the financial crisis dummy starts with the crash of Lehman Brothers on October $6^{\text {th }} 2008$ and ends on October $16^{\text {th }} 2009$ when the SMI was back again on the same index level as before the crash. The time dummy for the Zumwinkel-Affair starts one day after the arrest of Klaus Zumwinkel on February $15^{\text {th }}$ and lasts until the end of the inspected sample period on January $4^{\text {th }} 2011$. The arrest has also induced a notable temporary downturn shock in the SMI. Alternative time dummy specifications are discussed in the robustness section (2.2.3).

All the three used data series are integrated of order one. ${ }^{5}$ Thus, in order to avoid the risk of spurious regression, the original data series have been transformed to obtain the daily percentage changes that are from now on denoted as $\% \triangle S M I$, $\% \triangle V P B$, and $\% \triangle L L B$. The plot of the transformed series is shown in Figure 2.

4 Weekends and trading holidays have been removed from the sample.

5 Unit root tests of Dickey and Fuller (1979) (augmented) and Phillips and Perron (1988) and also stationary tests of KwIATKOWSKI et al. (1992) all suggest that the series are not stationary but integrated of order one. After differencing once (in this case computing daily percentage changes), the series are integrated of order zero. 
Figure 1: Daily Stock Prices of VPB and LLB compared to Swiss Market Index (SMI)

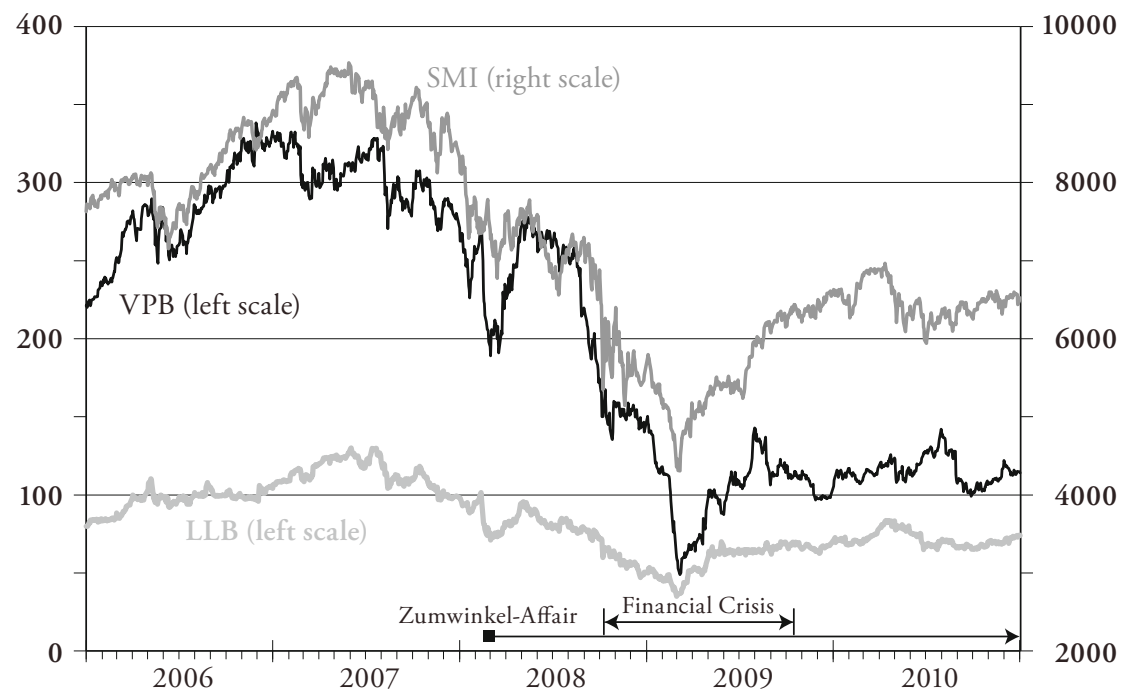

If the plots of the daily percentage changes of the three time series are compared, one recognizes that all the series feature visible volatility clustering, like a seismographic detection of equity risk. A rise of volatility is detectable during the period of the financial crisis (October 2008 until October 2009), but also (albeit comparably lower) at the time point when the data theft became public in February 2008.

It can also be observed that both stocks have a higher range and volatility than the Swiss Market Index, especially the VPB-stock (see Table 1). The stocks' standard deviations are higher than the market index's standard deviation, while all are alike when it comes to comparing their fourth moments: They all have a kurtosis that is considerably higher than 3 . Thus, the three time series have leptokurtic properties featuring "heavy-tails". ${ }^{6}$

6 The leptokurtic features and the pattern of autoregressive conditional heteroskedasticity can also be observed if ARCH-tests after ENGLE (1982) are carried out, the sample distributions are plotted and the correlograms of the squared variables are inspected. An inspection of the series' leptokurtic characteristics and related ARCH-tests can be found in BRUNHART (2012, pp. 44-48). 
Figure 2: Daily Percentage Changes of SMI (Middle Graph), VPB-Stock

Prices (Top Graph) and LLB-Stock Prices (Bottom Graph)
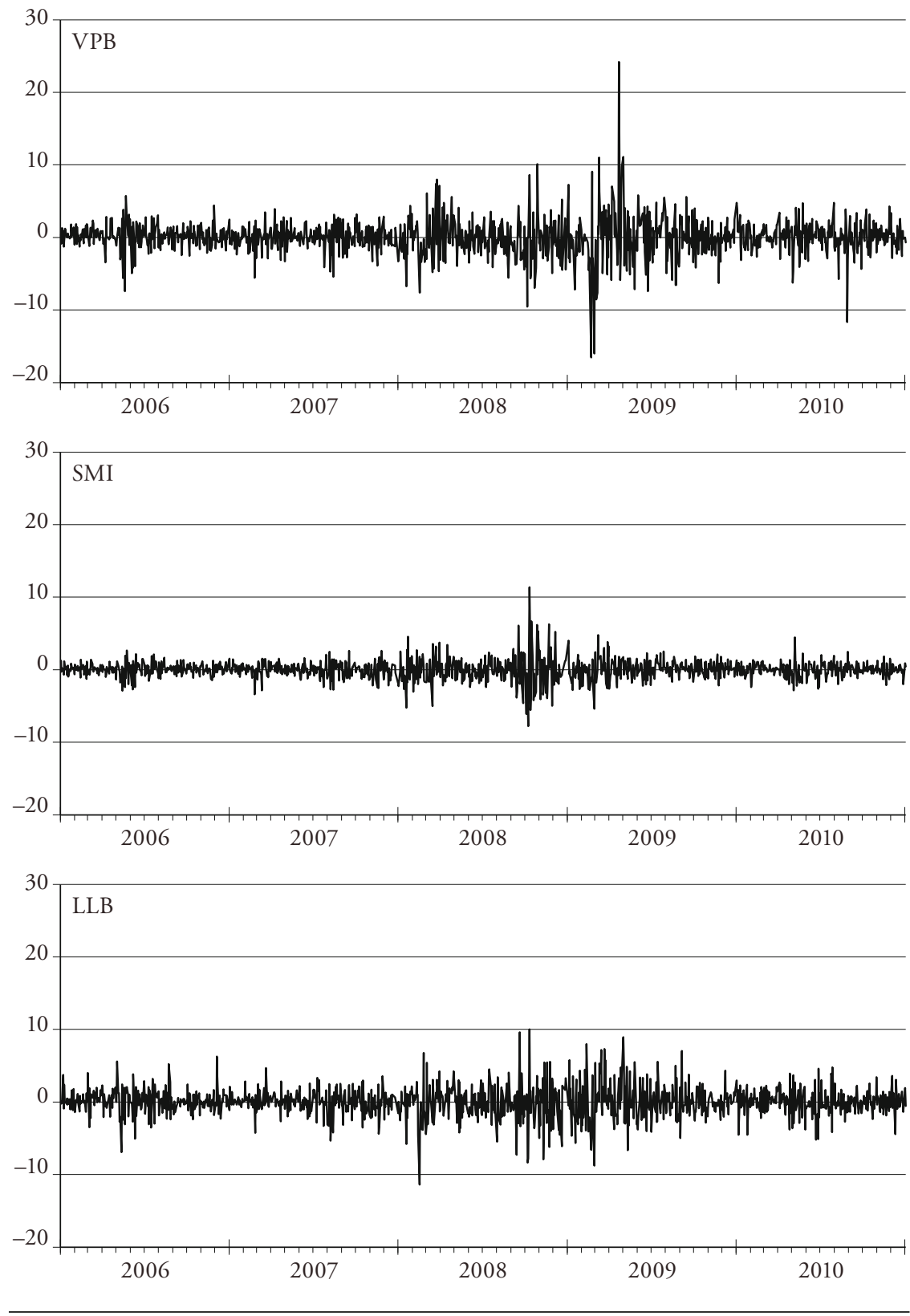

Swiss Journal of Economics and Statistics, 2014, Vol. 150 (3) 
Table 1: Descriptive Statistics of the Time Series

\begin{tabular}{lrrr}
\hline Descriptive Statistics & $\% \Delta V P B$ & $\% \Delta S M I$ & $\% \Delta L L B$ \\
\hline Mean (1 ${ }^{\text {st }}$ Moments) & -0.0224 & -0.0035 & 0.0149 \\
Median & 0.0000 & 0.0496 & 0.0000 \\
Maximum & 24.1782 & 11.3910 & 10.0000 \\
Minimum & -16.5276 & -7.7881 & -11.3918 \\
Standard Deviation (2 ${ }^{\text {nd }}$ Moments) & 2.4599 & 1.3427 & 2.0472 \\
Skewness ( ${ }^{\text {rd }}$ Moments) & 0.2726 & 0.3070 & -0.0167 \\
Kurtosis (4 $4^{\text {th }}$ Moments) & 15.0161 & 11.0651 & 6.3034 \\
\hline
\end{tabular}

\subsection{Augmented amalGARCH Model}

This section includes the amalGARCH-approach's model setup to investigate the impact of the Zumwinkel-Affair on the banks' stock values, the regression results along with various robustness checks and the analytical interpretation of the main results.

\subsubsection{Model Setup}

Instead of only estimating an ordinary mean equation (1) it is fruitful in the presence of leptokurtic features of the involved time series to also incorporate a variance equation (2) with the conditional variance ( $h_{t}$ in the variance equation), which accounts for the volatility clustering arising from the dependency of the conditional variance on previous shocks. The specification of the conditional variance resembles the conception of ENGLE (1982), who modelled the conditional variance as a function of the mean equation's past squared residuals. BollerSLEV (1986) and TAYLOR (1986) developed a more general approach additionally considering the possibility of an autocorrelated conditional variance. WeIss (1984) as well introduced a more general form of the original ARCH-model. He incorporated a dependency of the conditional variance on past squared observed values of the dependent variable of the mean equation $\left(Y_{t}\right)$, albeit with a mean adjustment that is not applied here. Note that Weiss (1984) implicitly also integrated the squared lagged form of the independent variables $X_{1}$ to $X_{k}$, as part of a linear predictor $\left(\hat{Y}_{t}\right)$ within the variance equation. ${ }^{7}$ The inclusion of independent

7 The linear predictor is the mean equation's linear prediction of $Y_{t}$ with an information set up to $t-1$. This term is subject to mean adjustment (see WeIss 1986, p. 109 and HaUser and Kunst 1993, p. 7). 
variables from the mean equation into the variance equation is labelled by the term "augmented" and therefore not part of the core classification that is just being introduced here (see Table 2). In a general-to-specific manner, which is executed in the main model set up of this papers' investigations, the mean equation is derived from a general autoregressive distributed lag model setting and the conditional variance shall be allowed to be a potential function of past residuals in squares, past conditional variances and the squared dependent variable. ${ }^{8}$

$$
\begin{gathered}
Y_{t}=\alpha_{1}+\sum_{z=1}^{l} \delta_{z} Y_{t-z}+\sum_{m=0}^{n} \beta_{1, m} X_{1, t-m} \\
+\sum_{c=0}^{d} \beta_{2, c} X_{2, t-c}+\ldots+\sum_{v=0}^{w} \beta_{k, v} X_{k, t-v}+u_{t} \\
u_{t} \mid \Omega_{t}-\mathrm{N}\left(0, h_{t}\right), \sigma_{t}^{2}:=h_{t} \\
h_{t}=\alpha_{2}+\sum_{i=1}^{p} \gamma_{i} u_{t-i}^{2}+\sum_{j=1}^{q} \phi_{j} h_{t-j}+\sum_{r=1}^{s} \rho_{r} Y_{t-r}^{2}
\end{gathered}
$$

The family of all possible combinations or amalgams of these mentioned approaches shall be called "amalGARCH $(p, q, s)$ ", where $p$ is the lag-length of the squared residual, $q$ the lag-length of the squared dependent variance and $s$ the lag-length of the dependent variable. As explained later on, this general-tospecific approach can be augmented by lagged independent variables (in squares) and dummy variables from the mean equation, but if desired also by variables that are not part of the mean equation. Table 2 summarizes and classifies the applied augmented amalGARCH $(p, q, s)$ and relates this approach, which turns out to be superior in the data application here, to popular models proposed in the literature. The amalGARCH-proceeding with the explicit modelling of dependent and independent variables in the variance equation enables a better understanding of the various channels of shock translation than the sole concentration on past residuals and past conditional variances. Nota bene: Applying all

8 I am thankful for the remark by Robert Kunst (University of Vienna) that this model is not identified if $Y$ is white noise. If autocorrelation of $Y$ is weak, it becomes difficult to separate the gamma and the rho terms.

9 The notation "amalGARCH" introduced here was inspired by HAUSER and Kunst (1993, p. 7) who state that the original approach of Weiss (1984) allows "... amalgams of Engle-type dependence on past errors..." and of the "...squared past observations of the process $Y_{t}$ itself." 
Table 2: Applied Augmented amalGARCH $(0,1,1)$ and Other Models within amalGARCH-Group

\begin{tabular}{|c|c|c|c|c|c|c|}
\hline & \multicolumn{3}{|c|}{$\begin{array}{l}\operatorname{amalGARCH}(p, q, s)- \\
\text { specifications }\end{array}$} & \multicolumn{3}{|c|}{ Augmentation } \\
\hline & \multirow{2}{*}{ 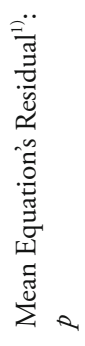 } & \multirow[b]{2}{*}{ 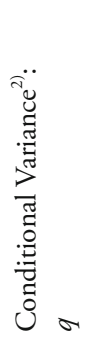 } & \multirow[b]{2}{*}{ 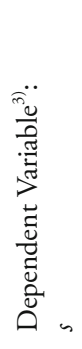 } & \multicolumn{2}{|c|}{$\begin{array}{l}\text { Independent } \\
\text { Variables }\end{array}$} & \multirow[b]{2}{*}{ 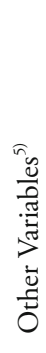 } \\
\hline & & & & 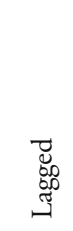 & 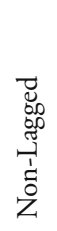 & \\
\hline ENGLE [1982]: ARCH & $\checkmark$ & & & & & \\
\hline WeIss [1984] & $\checkmark$ & & $\sqrt{ }^{7)}$ & $(\checkmark)^{6}$ & & \\
\hline BOLLERSLEV [1986]: GARCH & $\checkmark$ & $\checkmark$ & & & & \\
\hline Augmented amalGARCH $(0,1,1)$ & & $\checkmark$ & $\checkmark$ & $\checkmark$ & $\checkmark$ & $\checkmark$ \\
\hline
\end{tabular}

1) Past residuals (obtained from the mean equation) in lagged squared form with lag-length $p$.

2) Past conditional variance (obtained from the variance equation) in lagged form with lag-length $q$.

3) Dependent variable (from the mean equation) in lagged squared form with lag-length $s$.

4) Some or all variables from the mean equation (variables in squared form or dummy variables).

5) Variables that are not part of the mean equation in lagged or non-lagged and squared or nonsquared form.

6) Implicitly included as part of the mean-adjusted linear predictor of $Y_{t}$ (see footnote 7 of this paper).

7) Subject to mean adjustment.

the possible components of Table 2 simultaneously may yield invalid results (see footnote 11 for the application here), expressed for example by negative coefficients. This can usually be circumvented by setting either $p, q$ or $s$ to zero in the general-to-specific amalGARCH-modelling process that seeks to find optimality regarding model fit and analytical purpose. Such invalidities are not uncommon in the ARCH-model family and may also appear in ordinary GARCH-models (especially for high lag-orders).

The popular models included in Table 2 can be integrated into the proposed amalGARCH-notation: The ARCH-model by ENGLE (1982) would be termed as amalGARCH $(p, 0,0)$, the specification of WeIss $(1984)$ as amalGARCH $(p, 0, s)$ and the GARCH-model by Bollerslev (1986) as amalGARCH $(p, q, 0)$. 
The chosen model specification in Section 2.2.2 corresponds to an amal$\operatorname{GARCH}(0,1,1)$ additionally augmented by independent variables from the mean equation (\% $\% S M I_{t-1}^{2}$ and Zumwinkel-Affair time dummy) and the financial crisis time dummy that is not part of the mean equation. More precisely: The mean equation models the return performance of the stock value (either $\% \Delta V P B_{t}$ or $\left.\% \Delta L L B_{t}\right)$ and the variance equation contains the conditional variance as a measure for the risk of the respective stock value. As control variables in the mean equation the performance of the Swiss Market Index $\left(\% \Delta S M I_{t}\right)$ and the past performance of the bank's stock price (either $\% \Delta V P B_{t-1}$ or $\% \Delta L L B_{t-1}$ ) are used. The variable $\left(\% \Delta S M I_{t}\right.$ implicitly also controls for the heavy fluctuations during the financial crisis. Then, the additional effect (ceteris paribus) of the Zumwinkel-Affair is modelled by a time dummy from February $15^{\text {th }} 2008$ until January $4^{\text {th }} 2011$ and will be labelled as "data theft" in the following regression outputs. Of particular interest is the specification of the variance equation: The past squared residuals and the past conditional variances were supplemented by the independent variable and augmented by the other control variables from the mean equation (in lagged and squared form, ${ }^{10}$ except for the Zumwinkel dummy). They are also augmented by the financial crisis time dummy from October $6^{\text {th }}$ 2008 to October $16^{\text {th }} 2009$, which is not included into the mean equation.

\subsubsection{Estimation Results}

The following passages point out the main results obtained from the augmented amalGARCH( $(0,1,1)$-model, whose outputs are visible in Table 3 . The estimations of both stock values' regression equations contain 1256 observations after adjustments. The lag-lengths in the mean and variance equation have been determined with respect to the information criteria by AKaIKE (1974) and SCHWARZ (1978), also keeping in mind the conditions for a valid GARCH-model and the significance of the GARCH-coefficients. ${ }^{11}$

10 The reason for taking squares is to ensure that both past negative and past positive outbursts have the same (presumably increasing) effect on volatility measured by the conditional variance.

11 The information criteria clearly suggest a parsimonious amalGARCH $(0,1,1)$-specification for both stocks. Higher amalGARCH-orders (especially of past residuals) generate unacceptably many insignificant estimates and even negative coefficients, which is invalid. Also, incorporating past observations of the dependent variables plus past residuals into the VPB's variance equation yields invalid results in this application (indicated by negative signs of the past residual's coefficient). But: This only happens if the past conditional variance is also included at the same time and only in the case of the VPB's equation. This problem is resolved by setting either $p$ or $s$ to zero in the search for the optimal amalGARCH$(p, q, s)$. Also note that an 
Table 3: Estimation Output of the Proposed Augmented amalGARCH( $0,1,1)$-Model

\begin{tabular}{|c|c|c|}
\hline Dependent Variable & $\% \Delta V P B_{t}$ & $\% \Delta L L B_{t}$ \\
\hline \multicolumn{3}{|c|}{ (Conditional) Mean Equation } \\
\hline Constant & 0.0636 & $0.1123^{*}$ \\
\hline$\% \Delta V P B_{t-1}$ & -0.0121 & \\
\hline$\% \Delta L L B_{t-1}$ & & $-0.0900^{* * *}$ \\
\hline$\% \Delta S M I_{t}$ & $0.5936^{* * *}$ & $0.4168^{* * *}$ \\
\hline Data Theft & -0.0843 & -0.1102 \\
\hline \multicolumn{3}{|c|}{ (Conditional) Variance Equation: $h_{t}$} \\
\hline Constant & $0.3037^{* * *}$ & $0.4096^{* * *}$ \\
\hline$\hat{h}_{t-1}$ & $0.6466^{* * *}$ & $0.5329^{* * *}$ \\
\hline$\% \Delta V P B_{t-1}^{2}$ & $0.1083^{* * *}$ & \\
\hline$\% \Delta L L B_{t-1}^{2}$ & & $0.1647^{* * *}$ \\
\hline$\% \Delta S M I_{t-1}^{2}$ & $0.1695^{* * *}$ & $0.2514^{* * *}$ \\
\hline Financial Crisis & $1.9709^{* * *}$ & $1.2198^{* * *}$ \\
\hline Data Theft & $0.4542^{* * *}$ & $0.1683^{* *}$ \\
\hline
\end{tabular}

Notes: The respective p-values are indicated by stars $\left({ }^{*}: \mathrm{p}\right.$-value $\leq 0.10$ and $>0.05 ;{ }^{* *}$ : $\mathrm{p}$-value $\leq 0.05$ and $>0.01{ }^{* * *}$ : p-value $\left.\leq 0.01\right)$.

The influence on the daily stock prices' percentage change is captured by the mean equation: The constant is only significant (and only weakly) in the case of LLB, while the performance of the SMI is highly significant for both banks meaning that general market fluctuations are closely related to the stocks. The past performance of LLB's stock price, in contrast to VPB, plays also a role: Even though the coefficient of the lagged dependent variable is rather small, it is

amalGARCH $(0,1,0)$ without augmentation should not be applied. The proceeding was the following: First, the optimal values for $p, q$ and $s$ were determined according to the mentioned information criteria and other validity considerations. Then, it was checked if the full augmentation could be relaxed by removing one or more variables in the augmentation part (SMI and both time dummies). As it turned out, the full augmentation was rewarding for both stock values, regardless of the specifications of $p, q$ and $s$. Applications of other models such as the frequently used benchmark model GARCH $(1,1)$ are investigated in Appendix A.1. 
significant and negative. ${ }^{12}$ The time dummy capturing the impact of the "Zumwinkel-Affair" on daily returns is not significant, so no effect on average performance can be discovered.

As already noted, it is of central relevance to inspect the involved variables' effect on the stock prices' conditional variances. The influence on volatility as a measure for risk is modelled by the variance equation with the conditional variance as the explained variable. The following results regarding the variance equation apply for both stock values regressions: All the estimated coefficients of the included variables are statistically significant and with expected positive signs, meaning that they all have a traceable accumulating effect on risk. The constant and the past conditional variance as explanatory variables within the variance equation are both highly significant. Thus, there is a generally existent average risk not explained by the market risk or the other considered variables. The squared control variables $\% \Delta S M I_{t-1}^{2}$ and $\% \Delta V P B_{t-1}^{2}$ or $\% \Delta L L B_{t-1}^{2}$ are also highly significant. Most interestingly, the two dummy variables are highly significant. Hence, it is concluded that the financial crisis had a strong effect on volatility. Additionally, the data theft (Zumwinkel-Affair) also intensified the volatility/risk of the daily returns to a high extent. The magnitudes of the effects of affair and crisis on risk are visible in the plotted conditional standard deviations of Figure 3. ${ }^{13}$

Plotting the graph with the estimated conditional standard deviations for $\% \triangle V P B$, one can clearly observe the higher level of volatility beginning with the "Zumwinkel-Affair" and the even higher risk during the financial crisis. The conditional standard deviation plot also reflects the already mentioned strong volatility clustering indicating that risk is time-dependent. Plotting the graph with the estimated conditional standard deviations for $\% \triangle L L B$, it can be observed that volatility is rising with the beginning of the "Zumwinkel-Affair", but considerably less compared to the conditional variance graph of $\% \triangle V P B$. These plots

12 Interestingly, it turns out that there is a certain path dependency of the volatility of the examined dependent variable $\% \triangle L L B$ and that there is, in contrast to $\% \triangle V P B$, also significant autocorrelation of the variable $\% \triangle L L B$ itself: The lagged dependent variable $\% \triangle L L B_{t-1}$ is significant and the negative autocorrelation exhibits a significant Q-statistic after LJUNG and Box (1978), with a p-value of 0.028 for the first lag (and only for the first lag). This result is not in line with the market efficiency hypothesis.

13 After the incorporation of the variance equation, which accounts for the autoregressive conditional heteroskedasticity through the just outlined GARCH-approach, we observe that the squared residuals of the improved model are not autocorrelated anymore (in contrast to estimation without variance equation). 
Figure 3: Estimated Conditional Standard Deviations (\% $\triangle V P B$ Top Graph, $\% \triangle L L B$ Bottom Graph)
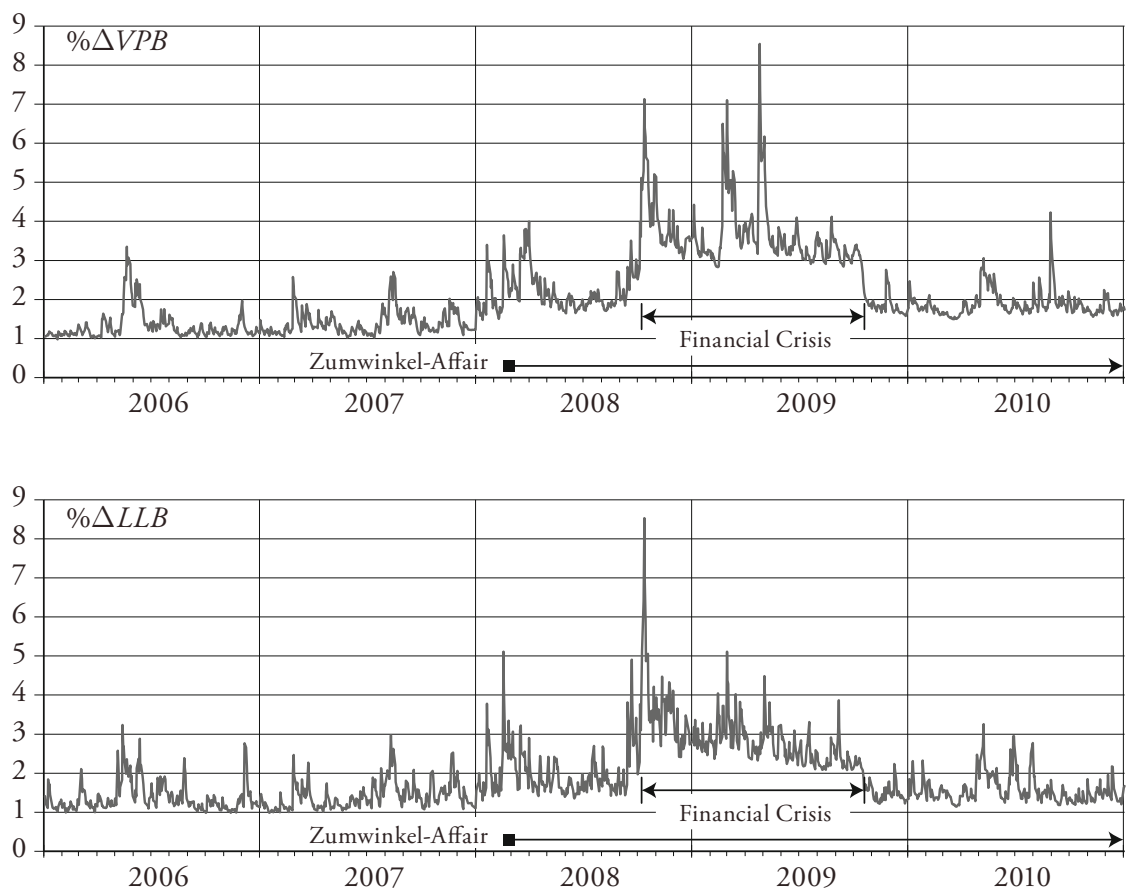

also underline another earlier finding from the estimation outputs: The financial crisis clearly had a cumulating impact on risk.

A shown in Appendix A.1, the applied augmented amalGARCH $(0,1,1)$ is, compared to ordinary GARCH-models, not only preferable because of the better understanding of the shock transmission channels but also according to the data fit in this application.

\subsubsection{Robustness Checks}

It is important to refer to other specifications that have been executed within the estimation frame of both stocks in order to obtain a more general base for drawing the essential conclusions. These modifications shall be outlined in the following.

It can be stated here that the chosen unconventional modelling of the dependence of the conditional variance (amalCARCH) is preferable to the conventional 
forms after Engle (1982), Bollerslev (1986) and also the specification following the main manner of WeIss (1984) in this context. Yet, the main analytical findings from Section 2.2.2 are insensitive to changes in the specification of the amalGARCH-part of the variance equation (see Appendix A.1).

The inclusion of the financial crisis dummy into the mean equation does not alter the main results, the coefficient is insignificant meaning that the stock performance did not suffer more severely from the financial crisis than the market (see Appendix A.2). Also, the main results are insensitive to the inclusion or exclusion of the constant in the mean equation. As an alternative indicator for the market fluctuations a sub-index has also been used instead of the SMI. This sub-index "SPI (financial institutes)" captures all financial institutes that are present at the Swiss Stock Exchange. However, the usage of this alternative indicator does not yield any changes worth mentioning. This result is not very surprising as visual and descriptive statistics suggest that both series SMI and SPI (financial institutes) are highly correlated. As it turns out, the inclusion of the TED spread as an alternative indicator for the financial crisis does not affect the sign or the significance of the dummy capturing the Zumwinkel-Affair. ${ }^{14}$ Along with the originally chosen time span used for the financial crisis time dummy other identifications of the relevant time span have been executed to check potential sensitivities of the results to different lengths of the financial crisis dummy. The crucial finding that the Zumwinkel-Affair had a significant (accumulating) effect on the risk of the banks' stock values is insensitive to the different lengths of the financial crisis dummy's time span (for detailed results see Appendix A.2). Another alternation of the chosen setting were three time dummies for a better separation of the data theft's short-run and long-run effects. ${ }^{15}$ Also in this setting, it can be deduced that both events, data theft and financial crisis, have boosted volatility of both banks' stock prices, but again no impact of the data theft on average performance can be detected.

14 The TED spread is the calculated difference between the interest rates of the 3 -months dollarLIBOR (interbank loans) and the interest rates of 3-months U.S. treasury bills. It captures the observed credit risk and is therefore a good indicator for the trust in the financial market. Detailed results of the inclusion of the TED spread into mean and variance equation are outlined in BRUNHART (2012, pp.39-41).

15 The first one is from the beginning of the original data theft dummy in February 2008 (arrest of Zumwinkel) until the beginning of the original financial crisis dummy starting with the collapse of Lehman Brothers in October 2008. The second has the same time span as the original financial crisis dummy (October 2008 until October 2009) and the third one lasts from the end of the second time dummy until the end of the sample (beginning of 2011). 
The also popular GARCH-M specification proposed by ENGLE, LiLIEN, and Robins (1987), which allows the conditional mean to directly depend on its own conditional variance, has also been estimated. The coefficient estimates for the independent variables in variance and mean equation were only slightly changed and the significance conclusions remained unchanged, while the GARCH-M-component in the mean equation appeared to be insignificant. Thus, the inspected stock prices are not directly dependent on their risk. A threshold GARCH model by Zakoian (1990) and Glosten, Jagannathan, and RunkLE (1993) has been executed as well. Doing so, the amalGARCH model has been extended by a multiplicative dummy that checks whether there has been a difference between the impact of negative shocks and positive ones. The optimal number of such TGARCH dummies has been chosen according to information criteria. The main results, especially concerning the significant impact of the data theft on the conditional variance of both stocks, appear insensitive to these changes. Furthermore, the main findings of the estimation equations for both banks, as shown in Table 3, are not sensitive to the assumptions on the error's conditional distribution. As an alternative to the chosen normal distribution the student's t-distribution, which was proposed by BollersLev (1987) in the context of finance data, has been applied. ${ }^{16}$ The findings of primary interest remain unchanged for both stocks, regarding the sign and magnitude of the important coefficients, and the p-values remain below 0.05 .

Hence, one can conclude for both stock return series that the most important results, such as the highly significant effect of the Zumwinkel-Affair on risk, do not change across the various alternative specifications. ${ }^{17}$ The estimation including the variables in differenced logarithms instead of percentage changes delivers similar results with the same conclusions.

As a crosscheck, the same estimations are also carried out for the Swiss banks Sarasin and Vontobel and compared with the results for Liechtenstein's banks. Of central concern is the crosscheck whether the magnifying effect of the data theft and the revelation of tax evaders (also the following international pressure on Liechtenstein and the investors' insecurity) as well had an effect on the Swiss banks. It turns out that no effect of the Zumwinkel-Affair on the Swiss stocks'

16 An ordinary augmented GARCH $(1,1)$ was applied and the t-distribution parameter was set according to an optimal log-likelihood.

17 This also holds for the inclusion of the stock returns of LLB into the VPB-model and vice versa. Also the inclusion of the interaction term DATATHEFT.\% $\triangle S M I$ does not affect the main results and the coefficient of the interaction term is not significant for both stock values' mean and variance equations. 
risk can be found: The coefficients are extremely small and not significant. Hence, the Zumwinkel-Affair seems to have magnified the volatility of stock values of Liechtenstein's banks but not of the Swiss banks, which is intuitive and additionally validates the chosen model. ${ }^{18}$

\subsection{Short-Run and Long-Run Event Studies}

The analysis of Section 2.2 showed that there were no middle- or long-term effects of the data theft on the mean of the stock value performance (only on risk). A useful complementary tool for the investigation of the Zumwinkel-Affair's mainly short-term but also long-term impacts on the stock returns are different types of event studies ${ }^{19}$ to assess abnormal behaviour of stock values compared to the whole stock market tendencies. The general framework in an event study is to have three different windows: The estimation window (here 120 or 529 trading days before the actual event), the event window (start of the Zumwinkel-Affair on February $14^{\text {th }}$ in 2008 until 59 or 727 trading days afterwards) and sometimes the post-event window (not included in these two event studies). In the so-called market model the stock value's return is related to the market's return. This relation is modelled as follows:

$$
Y_{t}=\alpha+\beta \cdot X_{t}+u_{t}
$$

In the application here, $Y_{t}$ is the daily percentage change of the investigated bank's stock value and $X_{t}$ the market return (measured by the percentage change of SMI). The equation of the market model serves as regression within the estimation window and its parameter values are in a next step used in the event window to predict the stock returns as a function of the market returns. For each time point of the event window, in this case each trading day, the difference of the predicted value and the actually observed stock return is retrieved. This difference for each time point is therefore the out-of-sample forecast error and is called "abnormal return" (AR). The cumulated abnormal returns (CAR) are the sum of all the abnormal returns in the considered time-window up to that particular time point.

18 Detailed results to the Swiss banks and more interpretations can be found in BrUnharT (2012, pp. 49-51).

19 Famous examples of event studies are Fama et al. (1969) and MacKinlay (1997). Useful overviews on event studies and related tests can be found in Pynnönen (2005) and Kothari and WARNER (2006). 
Table 4: GARCH-Models in Estimation Window (120 and 529 Trading Days before Arrest)

\begin{tabular}{|c|c|c|c|c|c|c|}
\hline \multirow[t]{2}{*}{ Dependent Variable } & \multicolumn{4}{|c|}{$\begin{array}{l}\% \Delta V P B_{t} \\
\qquad 120 \text { tradin }\end{array}$} & $\begin{array}{c}\% \Delta V P B_{t} \\
529 \text { trac }\end{array}$ & $\begin{array}{l}\% \Delta L L B_{t} \\
\text { ing days }\end{array}$ \\
\hline & \multicolumn{6}{|c|}{ (Conditional) Mean Equation } \\
\hline Constant & 0.0474 & 0.0515 & -0.0035 & 0.1056 & 0.0718 & $0.1083^{*}$ \\
\hline \multirow[t]{2}{*}{$\% \Delta S M I_{t}$} & $0.6481^{* * *}$ & $0.6872^{* * *}$ & $0.3681^{* * *}$ & $0.4264^{* * *}$ & $0.6024^{* * *}$ & $0.4887^{* * *}$ \\
\hline & \multicolumn{6}{|c|}{ (Conditional) Variance Equation: $h_{t}$} \\
\hline Constant & & 0.3687 & & $1.3976^{* * *}$ & $0.2849^{* *}$ & $0.5743^{* * *}$ \\
\hline$\hat{u}_{t-1}^{2}$ & & 0.1795 & & $0.3327^{*}$ & $0.1857^{* * *}$ & $0.1804^{* * *}$ \\
\hline$\hat{h}_{t-1}$ & & $0.6663^{* *}$ & & & $0.6807^{* * *}$ & $0.5460^{* * *}$ \\
\hline
\end{tabular}

Notes: The respective p-values are indicated by stars $\left(^{*}\right.$ : $\mathrm{p}$-value $\leq 0.10$ and $>0.05 ;{ }^{* *}$ : $\mathrm{p}$-value $\leq 0.05$ and $>0.01{ }^{* * *}$ : p-value $\left.\leq 0.01\right)$.

It is straightforward to apply a GARCH-setting in this context to model the error's conditional variance in the estimation window regression. ${ }^{20}$ An ordinary $\operatorname{GARCH}(p, q)$ is used, which corresponds to a non-augmented amalGARCH $(p, q, 0)$. The lag structure in the variance equation was again chosen with respect to the information criteria by AKaIKe (1974) and SCHWARZ (1978) and GARCH-models' validity requirements, the maximal lag-length was 5. Table 4 shows the regression results for both banks in the estimation window (120 observations from August $22^{\text {nd }}$ in 2007 until February $13^{\text {th }}$ in 2008).

The regression equations of Table 4 can then be used in the event period (60 observations from February $14^{\text {th }}$ in 2008 until May $13^{\text {th }}$ in 2008) to compute the abnormal returns and the cumulative abnormal returns for both banks' stocks. These returns are visible in Figure 4.

For each time point $n$ in the event window (beginning with the arrest of Zumwinkel), the t-test statistic for the null hypothesis that the cumulated abnormal returns are zero is of the following form:

20 Also, an ordinary least squares regression without variance equation has been carried out for the 120 trading day estimation window to obtain the cumulated abnormal returns and the residual's sample variance (output in Table 4). Since the results and the corresponding abnormal returns are very similar to the GARCH-approach, the ordinary regression approach was abandoned in the further examinations. 
Figure 4: Banks' Abnormal Returns (AR) and Cumulated Abnormal Returns (CAR), 60 Trading Days

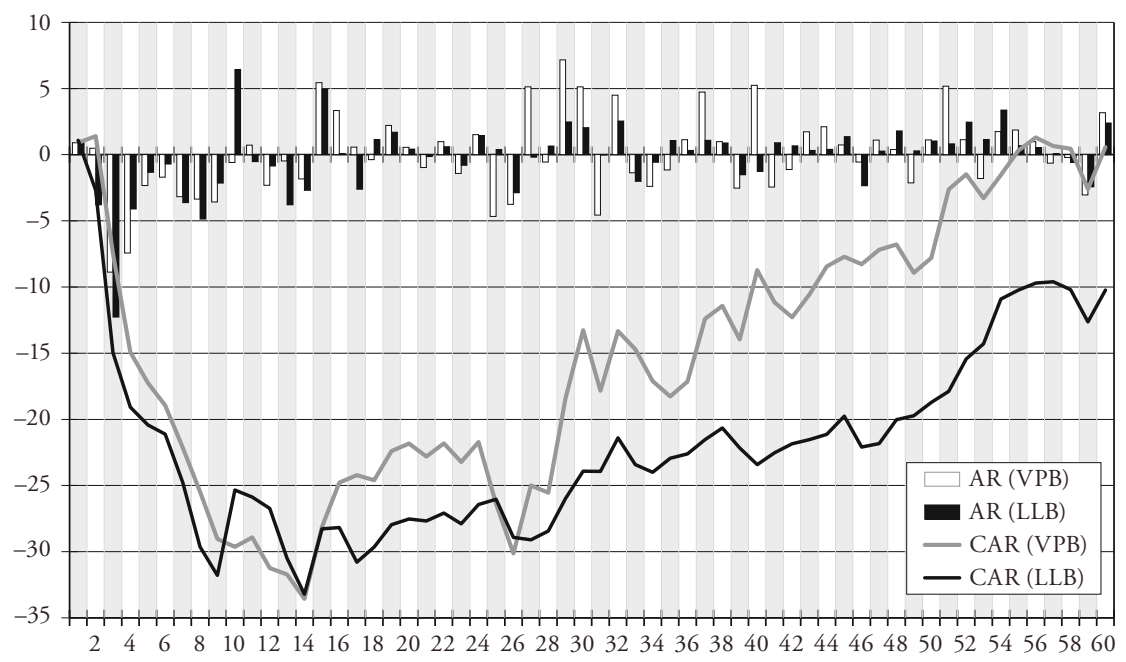

$$
\frac{C A R_{n}}{\sqrt{\operatorname{var}\left[C A R_{n}\right]}}
$$

To carry out the hypothesis test a choice of a measure for the cumulated abnormal returns' variance is required. The variance of the cumulated abnormal return for each time point is the sum of the abnormal returns' variances up to that considered time point (see MacKinlay 1997, p. 24). One possibility to obtain a proxy for the variance of the abnormal returns would be the sample variance of the estimation window's residual. Another possibility in this context is using the conditional variance $h_{t}$ for each time point $n$, inasmuch as a GARCH-approach was applied for the computation of the abnormal returns.

The test statistics of both approaches and both banks along with the two-sided confidence intervals are plotted in Figure 5. The graphic impression from Figure 4 , namely the negatively biased abnormal returns in the beginning of the event window, is supported by the cumulative returns, which are not significantly different from zero anymore after about 30 trading days. Thus, there was a negative short-term impact of Zumwinkel's arrest on the daily returns of both banks' stock values. The event's negative impact started after two days after the event and vanished around 30 trading days later. 
Figure 5: Significance Tests of Cumulated Abnormal Returns, 0 to 60 Trading Days after Event
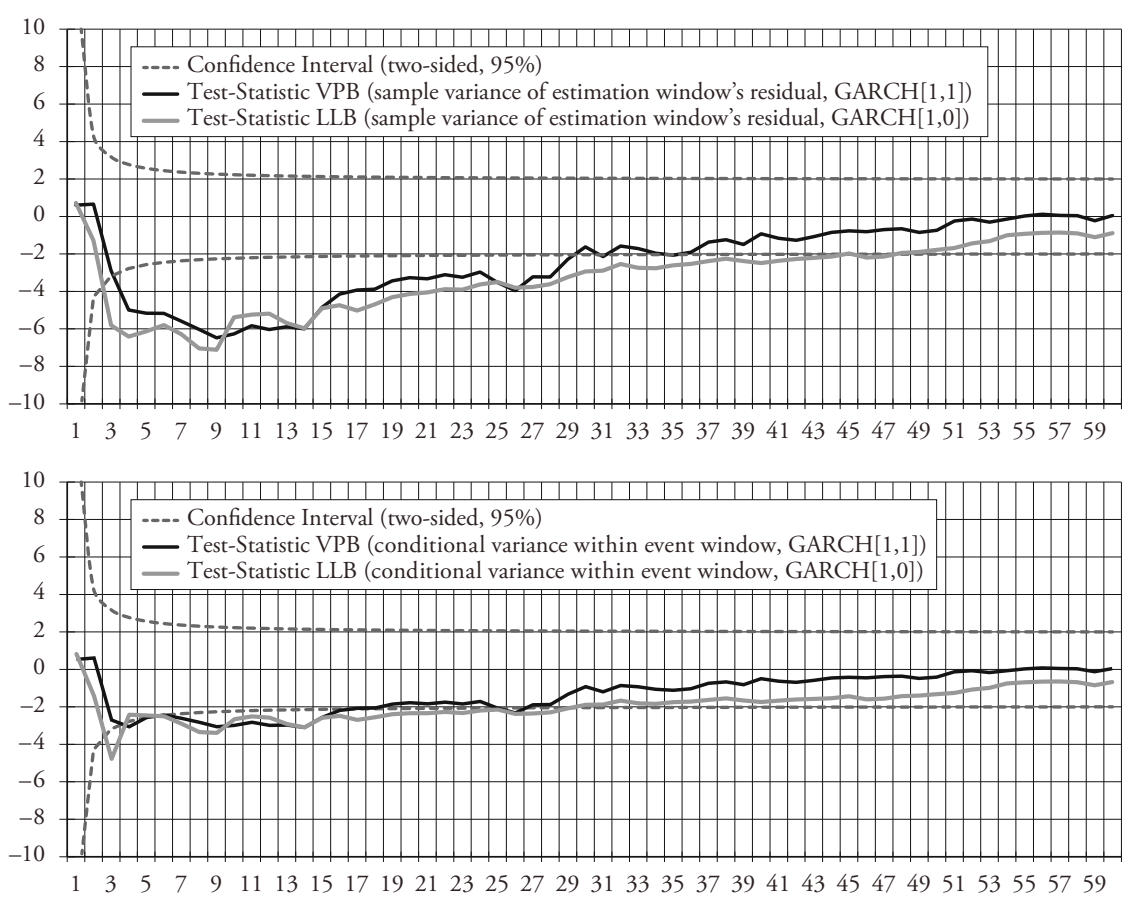

To examine the long-term effects the same exercise can be done for the entire sample. Doing so, the estimation window now begins on January $1^{\text {st }} 2006$ and the event window ranges from February $14^{\text {th }} 2008$ until the end of the sample on January $4^{\text {th }} 2011$. Hence, the estimation window includes 529 observations and the event window from Zumwinkel's arrest on 728 days. The estimation results are listed in Table 4. Conditional variances from the GARCH-model are applied for this long-term analysis, since the application of a constant sample variance is not very rewarding in the presence of autoregressive conditional heteroskedasticity already detected earlier in this paper, especially in a long-term frame.

Beyond the very immediate effect just shown, only around the beginning of 2009 there is a period with cumulated abnormal returns that are significantly different from zero (see Figure 6 for test statistics of both stock values). That period was the financial crisis' high noon and it is not surprising that the two financial stock values suffered more than the whole market portfolio (SMI), regardless of the 
Figure 6: Significance Tests of Cumulated Abnormal Returns, 0 to 727 Trading Days after Event

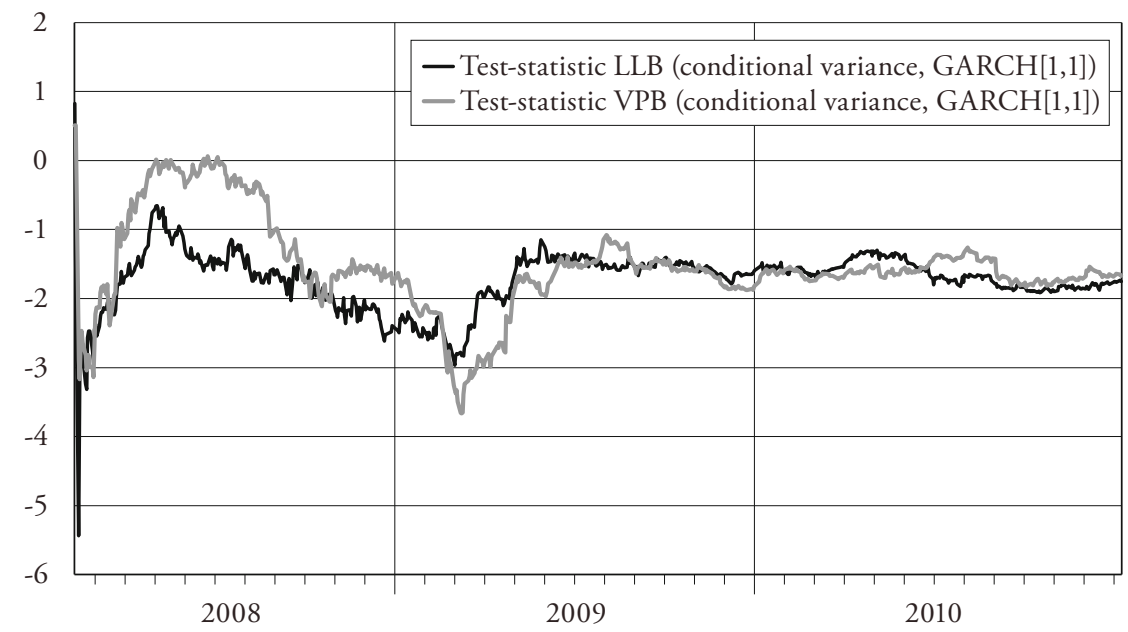

Zumwinkel-Affair. The long-run exhibits no cumulated abnormal returns significantly different from zero consulting two-sided significance bounds, 2.58 (99\%) or 1.96 (95\%). The finding of the previous section (2.2), that the Zumwinkel-Affair had no lasting effect on mean performance, is therefore supported.

\subsection{Interpretation und Summary of Findings}

The main analytical findings emerging from the amalGARCH-models explained in Section 2.2 and from the event study carried out in Section 2.3 can be summed up and interpreted as follows:

- Accumulating effect of Zumwinkel-Affair on risk: While the data theft dummy showed no significant impact on the average return performance of the two stock values' daily percentage changes, there is striking evidence that the data theft and the resulting affair had a deep impact on risk. The impact of the data theft time dummy on risk is significant for both stocks' conditional variances. However, the impact is higher for the VPB-shares than for the LLB-shares.

- Financial crisis had an increasing effect on risk: The volatility was directly affected by the financial crisis, which is indicated by the significant dummy in the variance equation. This holds for both stock return series. 
- Strong volatility clustering is present for both stocks: The conditional risk is clearly time-dependent, this was shown in different tests indicating heteroskedasticity, by the significant lagged variables in the variance equation and by the conditional variance graph and the conditional variance series' strong autocorrelation.

- Past (negative or positive) shocks boost volatility: Both stocks' conditional variances are very sensitive to past shocks, which is expressed by the highly significant positive coefficients of the lagged squared observations of the percentage change of the SMI and of the percentage change of the stock prices in the variance equation. This finding is of course related to the statement about the volatility clustering made before.

- Close relation to the market: Both the performance and the volatility of the two stocks are closely linked to the general market fluctuations, the influence of the SMI is significant in the mean and in the variance equation of the stocks.

- No effect of Zumwinkel-Affair on daily returns' means: Surprisingly, the Zumwinkel-Affair does not seem to have an effect on the mean of both banks' stock returns (only on their risk, which was mentioned earlier). The introduced data theft time dummy is insignificant in the amalGARCH mean equation. The event study detects only very immediate and short effects, but none in the long-rum and therefore supports the findings of the augmented amalGARCH-model. ${ }^{21}$

As pointed out in Section 2.2.3, the just mentioned findings answering the main objects of investigation were robust across all the applied variations in model types and specifications.

\section{Conclusions}

During a time of very good performance in the middle of the first decade of the current century the financial sector in Liechtenstein was flourishing in line with a general national and international economic expansion phase. But with the peak in 2007 and the ongoing start of the American sub-prime crisis the banking sector has faced rising pressure. The following financial crisis and the Zumwinkel-Affair affecting Liechtenstein's economy as a whole were a huge challenge, maybe the most turbulent time in Liechtenstein's recent economic history

21 If the financial crisis dummy is also included into the mean equation, the coefficient is insignificant. Hence, it can be argued that the two inspected stock values did not suffer to a higher extent than the market from the financial crisis. 
and came along with a deep transformation process of its whole financial sector. This empirical paper features augmented amalGARCH-models and event study regressions and is devoted to the impacts of the affair on stock values of banks in Liechtenstein.

The applied amalGARCH-models indicate a clearly accumulating effect of the Zumwinkel-Affair, separated from the also accumulating impact of the financial crisis, on the investigated stock values' volatility. In the course of this project it has therefore been shown that insecurity concerning the examined stock prices rose within the analysed time period and became manifest in increasing risk. The Zumwinkel-Affair's effect played an important role in this process. It is not easy to judge how immediately this insecurity came from the data theft itself, but it is very reasonable to argue that it occurred from a combination of the introductorily mentioned factors, such as the high political pressure, capital outflow, political reforms, and the transformation process within Liechtenstein's financial sector. Surprisingly, both the amalGARCH-models and event studies reveal that there was only a short-run effect of the Zumwinkel-Affair on the stock returns' average level, which vanished around 30 days after Zumwinkel's arrest. These main findings, along with further conclusions, appear to be insensitive to the whole variety of applied model types and specifications.

The applied amalGARCH-frame includes possible amalgams of the approaches of ENGLe (1982), Weiss (1984) and Bollerslev (1986)/TAylor (1986) and enables a better understanding via which specific channels past shocks translate into rising volatility of the stock prices compared to the widely used settings by the prementioned authors. The general allowance for the translation via all the possible channels (past shocks in the residuals, past shocks in dependent and independent variables and autocorrelation of the conditional variance) led to the newly introduced amalGARCH$(p, q, s)$-term classifying popular specifications of the conditional variance's modelling within one group.

There are also other (econometrically) important features of the applied setup: There is strong evidence that the chosen augmented amalGARCH $(0,1,1)$-model is superior in this application to the popular ordinary and "non-augmented" GARCH $(1,1)$-approach, for example according to information criteria. It is also preferable to the augmented GARCH $(1,1)$-specification, albeit with similar coefficient estimates considering the main variables of interest. As shown, the proposed setting of this contribution therefore outperforms the widely applied specifications after ENGLE (1982) and Bollerslev (1986) that both do not include variables' past observations in the variance equation and also the less known specification after WeIss (1984) which does include them but does not incorporate past conditional variances. This unexpected econometric finding supports the chosen 
approach beyond its predominance in analytical scope. Hence, the application of a general amalGARCH-frame (with potential augmentations) seems rewarding from both an econometric and an analytical prospective and can be applied to all possible investigations of shock events.

\section{A. Appendix}

\section{A.1 Alternative amalGARCH-Approaches}

Besides the applied amalGARCH $(0,1,1)$, two benchmark models are executed. These benchmark models are an augmented $\operatorname{GARCH}(p, q)$ and a non-augmented $\operatorname{GARCH}(p, q)^{22}$. As it turns out, very parsimonious specifications are optimal $(p=1, q=1)$. Lag-lengths are specified with regard to information criteria and validity considerations. Table 5 exhibits an overview of the described competing models with the different specifications of the variance equation. It is visible that the coefficient estimates of the important variables are similar considering sign, significance and magnitude of the coefficients. Also the patterns of the estimated conditional standard deviation gained from the variance equation are comparable for the three approaches (see BRUNHART 2012, pp.36-37). The important results are robust to changes in the specification. If information criteria are consulted it turns out that the applied setting, the augmented amalGARCH $(0,1,1$,$) , outper-$ forms the other two benchmarking approaches in this application. ${ }^{23}$

22 In the introduced notation, these models are augmented and non-augmented $\operatorname{amalGARCH}(p, q, 0)$-models.

23 It can be argued that it is not beneficial to gauge if a difference in an information criterion's values between two (nested or non-nested) models is significant, as this decision is already implicitly included in the criterion's choice (see Kunst 2003). Also, the fact that these information criteria already incorporate a "likelihood ratio test choice" is mentioned in BURNHAM and Anderson (2004) and Stoica, Selén and Li (2004). 
Table 5: Competing Models with Different Specifications of the Variance Equation

\begin{tabular}{|c|c|c|c|c|c|c|}
\hline Dependent Variable & & $\% \Delta V P B_{t}$ & & & $\% \Delta L L B_{t}$ & \\
\hline & 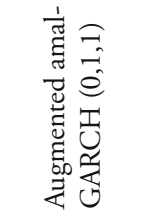 & 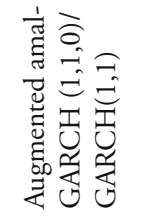 & 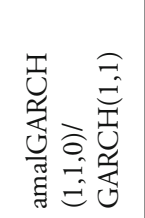 & 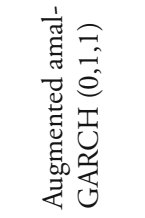 & 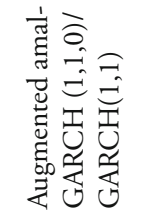 & 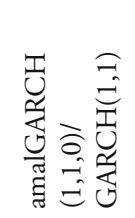 \\
\hline & \multicolumn{6}{|c|}{ (Conditional) Mean Equation } \\
\hline Constant & 0.0636 & 0.0635 & 0.0725 & $0.1123^{*}$ & $0.1089^{*}$ & 0.0769 \\
\hline$\% \Delta V P B_{t-1}$ & -0.0121 & -0.0108 & -0.0098 & & & \\
\hline$\% \Delta L L B_{t-1}$ & & & & $-0.0900^{* * *}$ & $-0.0809^{* * *}$ & $-0.0801^{* * *}$ \\
\hline$\% \Delta S M I_{t}$ & $0.5936^{* * *}$ & $0.5647^{* * *}$ & $0.5602^{* * *}$ & $0.4168^{* * *}$ & $0.4281^{* * *}$ & $0.4400^{* * *}$ \\
\hline \multirow[t]{2}{*}{ Data Theft } & -0.0843 & -0.0770 & -0.0746 & -0.1102 & -0.0994 & -0.0655 \\
\hline & \multicolumn{6}{|c|}{ (Conditional) Variance Equation: $h_{t}$} \\
\hline Constant & $0.3037^{* * *}$ & $0.3460^{* * *}$ & $0.0468^{* * *}$ & $0.4096^{* * *}$ & $0.5797^{* * *}$ & $0.2726^{* * *}$ \\
\hline$\hat{u}_{t-1}^{2}$ & & $0.1502^{* * *}$ & $0.0923^{* * *}$ & & $0.2342^{* * *}$ & $0.1960^{* * *}$ \\
\hline$\hat{h}_{t-1}$ & $0.6466^{* * *}$ & $0.6760^{* * *}$ & $0.9062^{* * *}$ & $0.5329^{* * *}$ & $0.5172^{* * *}$ & $0.7430^{* * *}$ \\
\hline$\% \Delta V P B_{t-1}^{2}$ & $0.1083^{* * *}$ & & & & & \\
\hline$\% \Delta L L B_{t-1}^{2}$ & & & & $0.1647^{* * *}$ & & \\
\hline$\% \Delta S M I_{t-1}^{2}$ & $0.1695^{* * *}$ & & & $0.2514^{* * *}$ & & \\
\hline Financial Crisis & $1.9709^{* * *}$ & $1.8041^{* * *}$ & & $1.2198^{* * *}$ & $1.6014^{* * *}$ & \\
\hline \multirow[t]{2}{*}{ Data Theft } & $0.4542^{* * *}$ & $0.4516^{* * *}$ & & $0.1683^{* *}$ & $0.1991^{* *}$ & \\
\hline & \multicolumn{6}{|c|}{ Measures of Fit } \\
\hline $\mathrm{R}^{2}$ & 0.1254 & 0.1242 & 0.1238 & 0.0772 & 0.0776 & 0.0777 \\
\hline Adjusted $\mathrm{R}^{2}$ & 0.1233 & 0.1221 & 0.1218 & 0.0750 & 0.0754 & 0.0755 \\
\hline $\begin{array}{l}\text { Akaike Info } \\
\text { Criterion }\end{array}$ & 4.1469 & 4.1690 & 4.1937 & 3.9464 & 3.9666 & 3.9993 \\
\hline $\begin{array}{l}\text { Schwarz Info } \\
\text { Criterion }\end{array}$ & 4.1877 & 4.2058 & 4.2224 & 3.9873 & 4.0034 & 4.0279 \\
\hline
\end{tabular}

Notes: $\hat{u}_{t-1}^{2}=$ lagged squared residual from mean equation. The relevant $\mathrm{p}$-values are indicated by stars $\left(*\right.$ : p-value $\leq 0.10$ and $>0.05 ;{ }^{* *}$ : p-value $\leq 0.05$ and $>0.01 ;{ }^{* * *}$ : p-value $\left.\leq 0.01\right)$. See Section 2.2 for the theoretical equation setup and estimation results of the main amalGARCH-models. 


\section{A.2 Alternative Time Spans of Financial Crisis Dummy}

As stated in the robustness checks of Section 2.2.3, an incorporation of the financial crisis dummy also into the mean equation is worth paying attention to. In the case of the mean equation, the time dummy can be interpreted as the additional effect of the crisis beyond the crisis' influence that is already captured by the bad performance of the SMI. This dummy therefore checks if the stock value has suffered more severely (or less) compared to the market regarding the average returns. The insignificance of the time dummy in the mean equation indicates that there was no additional ceteris paribus effect. Another fact contributes to the insignificance, which even remains if the SMI-variable is removed from the estimation: Inspecting Figure 2 it can be observed that not only the SMI fully recovers from the sharp downturn (the time span dummy was set according to this fact on purpose) but also the stock prices recover as the variables are highly correlated. Thus, the effects during the downturn and the upturn cancel out in the mean equation.

It is useful to allow for different lengths of the chosen time period of the financial crisis time dummy. In Section 2.1, the motivation for the original choice of the two time dummies' time span is already outlined. Along with the original time span (labelled with "Financial Crisis" in Figure 7) from October $6^{\text {th }} 2008$ to October $16^{\text {th }} 2009$ with the SMI as reference two other time spans have been applied: As second time span a shorter period is used and just covers the sharp decline from October $6^{\text {th }} 2008$ until March $9^{\text {th }} 2008$, again with the SMI as reference for the downturn (labelled with "Financial Crisis (Decline)" in Figure 7). A longer period, which relies on the TED spread as reference (see footnote 14), has also been considered. Apart from the visual detection of the visible beginning of the financial crisis by inspecting the TED chart, the median of the TED spread serves as a useful threshold for a more precise detection of the timing of the financial crisis (see BRUnHART 2012, p. 42). The TED spread exceeds the median of 38 on April $25^{\text {th }} 2007$ and does not score below 38 until August $24^{\text {th }} 2009$. This time span has been chosen to set the length for the longest period of the financial crisis time dummy (labelled in Figure 7 as "Financial Crisis (long)").

Only for the shortest period (the downturn phase without recovery) the financial crisis dummy shows significance in the mean equation of the VPB-stocks, while it shows no significance within the mean equation of the LLB-stock for all various lengths of the financial crisis dummy. If the SMI is removed from the mean equation then the short financial crisis dummy becomes significant in the mean equation with the LLB-stock and the VPB-stock as dependent variable. 
Figure 7: Different Specifications of the Financial Crisis Time Dummy's Length

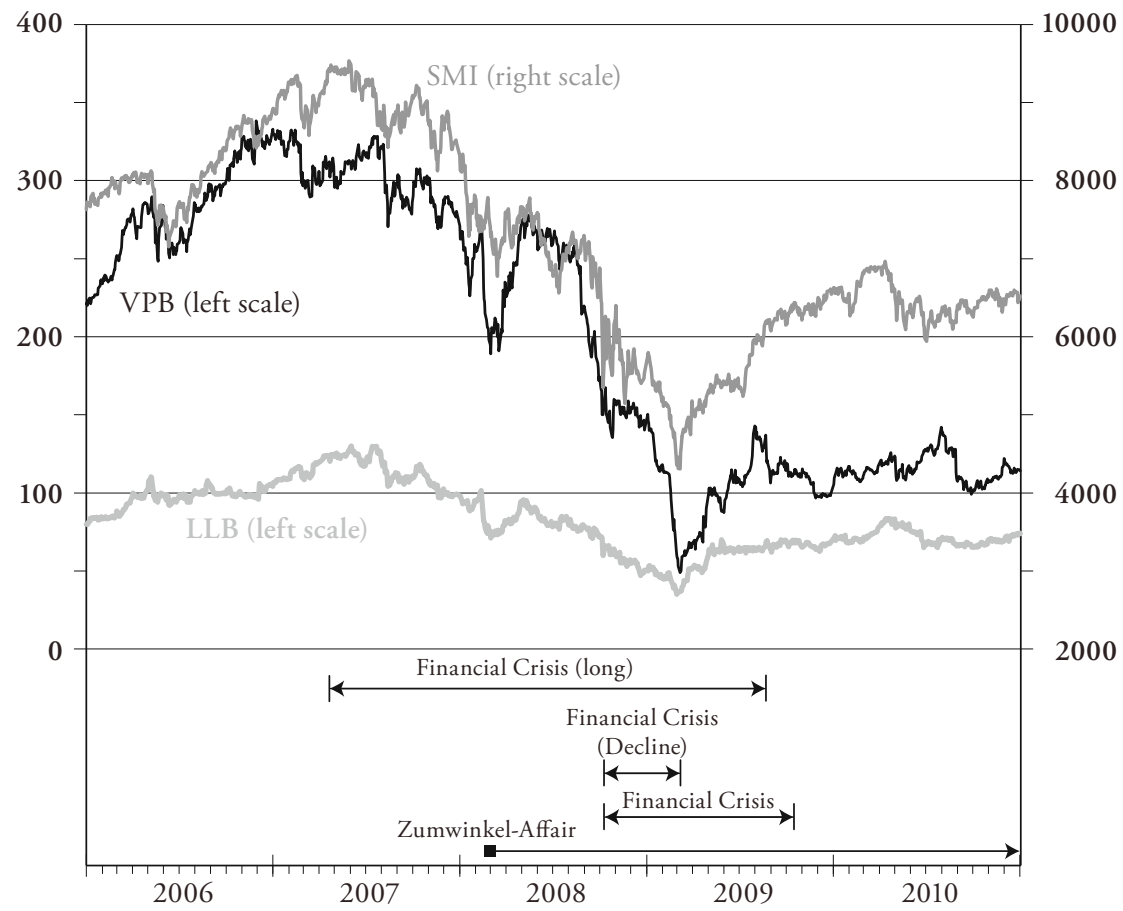

Hence, the financial crisis had no impact on average stock returns that was worse than the impact on the market (not in the downward phase and not if the recovery period is included into the time definition of the financial crisis). When it comes to the average performance, the stocks only suffered from the financial crisis in the downturn phase. The LLB-stock was hit comparably to the market, the VPB-stock performed worse.

The originally chosen time period appears to be the most appropriate as the emphasis should be on the most suitable time period concerning the variance equation which is of main interest in this contribution's analysis. The inclusion of some recovery into the chosen time period seems fairly reasonable as the financial crisis was surely not overcome by the reaching of the lowest trough of the Swiss Market Index in March 2009. During the recovery period afterwards the market was still affected by high insecurity and volatility. Also, the information 
Table 6: Competing Models with Different Time Periods of the Financial Crisis Dummy

\begin{tabular}{lccc|ccc}
\hline Dependent Variable & \multicolumn{3}{c|}{$\% \Delta V P B_{t}$} & \multicolumn{3}{c}{$\% \Delta L L B_{t}$} \\
\hline & \multicolumn{5}{c}{ (Conditional) Mean Equation } \\
\hline Constant & 0.0636 & 0.0683 & 0.1017 & $0.1123^{*}$ & $0.1142^{*}$ & $0.1545^{* *}$ \\
$\% \Delta V P B_{t-1}$ & -0.0121 & -0.0041 & -0.0000 & & & \\
$\% \Delta L L B_{t-1}$ & & & & $-0.0899^{* * *}$ & $-0.0925^{* * *}$ & $-0.0954^{* * *}$ \\
$\% \Delta S M I_{t}$ & $0.5936^{* * *}$ & $0.5847^{* * *}$ & $0.5894^{* * *}$ & $0.4167^{* * *}$ & $0.3983^{* * *}$ & $0.3989^{* * *}$ \\
Financial Crisis & -0.0198 & & & 0.0785 & & \\
Financial Crisis (Short) & & $-0.8708^{* *}$ & & & -0.5195 & \\
Financial Crisis (Long) & & & -0.1147 & & & -0.1239 \\
Data Theft & -0.0816 & -0.0369 & -0.0859 & -0.1226 & 0.0680 & -0.0933 \\
\hline
\end{tabular}

(Conditional) Variance Equation: $h_{t}$

\begin{tabular}{lcll|l|ll}
\hline Constant & $0.3034^{* * *}$ & $0.0576^{* * *}$ & $0.0663^{* * *}$ & $0.4093^{* * *}$ & $0.3248^{* * *}$ & $0.2505^{* * *}$ \\
$\hat{h}_{t-1}$ & $0.6469^{* * *}$ & $0.8832^{* * *}$ & $0.8601^{* * *}$ & $0.5331^{* * *}$ & $0.5810^{* * *}$ & $0.6199^{* * *}$ \\
$\% \Delta V P B_{t-1}^{2}$ & $0.1082^{* * *}$ & $0.0636^{* * *}$ & $0.0802^{* * *}$ & & & \\
$\% \Delta L L B_{t-1}^{2}$ & & & & $0.1646^{* * *}$ & $0.1723^{* * *}$ & $0.1703^{* * *}$ \\
$\% \Delta S M I_{t-1}^{2}$ & $0.1695^{* * *}$ & $0.0593^{* * *}$ & $0.0572^{* * *}$ & $0.2514^{* * *}$ & $0.2431^{* * *}$ & $0.2280^{* * *}$ \\
\hline Financial Crisis & $1.9699^{* * *}$ & & & $1.2153^{* * *}$ & & \\
\hline Financial Crisis (Short) & & $0.2193^{* *}$ & & & $1.2230^{*}$ & \\
\hline Financial Crisis (Long) & & & 0.0327 & & & 0.0987 \\
\hline Data Theft & $0.4537^{* * *}$ & $0.1099^{* * *}$ & $0.1504^{* * *}$ & $0.1684^{* *}$ & $0.2476^{* * *}$ & $0.2169^{* * *}$ \\
\hline & & & \multicolumn{1}{c}{ Measures of Fit } & & \\
\hline $\mathrm{R}^{2}$ & 0.1254 & 0.1365 & 0.1266 & 0.0773 & 0.0817 & 0.0777 \\
\hline Adjusted R & 0.1226 & 0.1338 & 0.1238 & 0.0743 & 0.0788 & 0.0748 \\
\hline Akaike Info Criterion & 4.1484 & 4.1649 & 4.1708 & 3.9478 & 3.9580 & 3.9633 \\
\hline Schwarz Info Criterion & 4.1934 & 4.2098 & 4.2158 & 3.9928 & 4.0029 & 4.0083 \\
\hline
\end{tabular}

Notes: The relevant p-values are indicated by stars $\left(^{*}\right.$ : p-value $\leq 0.10$ and $>0.05 ;{ }^{* *}$ : p-value $\leq 0.05$ and $>0.01 ;{ }^{* * *}$ : p-value $\left.\leq 0.01\right)$. See Section 2.2 for the theoretical equation setup and estimation results of the main GARCH-models. 
criteria are optimized in that setting of the financial crisis time dummy's length. The longest period seems too long in this context. ${ }^{24}$

All the relevant estimation results are listed in the output of Table 6 and can be summarized as follows. The crucial finding that the Zumwinkel-Affair had a significant (accumulating) effect on the risk of the banks' stock values is insensitive to the different lengths of the time span of the financial crisis dummy and also insensitive to the inclusion or exclusion of a financial crisis dummy in the mean equation (the exclusion yields a better data fit according to information criteria, though). Also, the effect of the financial crisis on risk vanishes in the longest time period specification of the financial crisis time dummy. This is the case within the variance equation of both stock values.

\section{References}

Akaike, Hirotugu (1974), "A New Look at the Statistical Model Identification", IEEE Transactions on Automatic Control, 19(6), pp.716-723.

Asteriou, Dimitrios, and Simon Price (2001), "Political Instability and Economic Growth: UK Time Series Evidence", Scottish Journal of Political Economy, 48(4), pp. 383-399.

Bollerslev, Tim (1986), "Generalized Autoregressive Conditional Heteroskedasticity”, Journal of Econometrics, 31(3), pp.307-327.

Bollerslev, Tim (1987), "A Conditionally Heteroskedastic Time Series Model for Speculative Prices and Rates of Return," Review of Economics and Statistics, 69, pp. 542-547.

Brunhart, Andreas (2012), "Stock Market's Reactions to Revelation of Tax Evasion: An Empirical Assessment”, KOFL Working Papers No. 9, Konjunkturforschungsstelle Liechtenstein.

Burren, Daniel, and Klaus Neusser (2010) "The Decline in Volatility of US GDP Growth", Applied Economics Letters, 17, pp. 1625-1631.

Burnham, Kenneth P., and David R. Anderson (2004), "Multimodel Inference: Understanding AIC and BIC in Model Selection", Sociological Methods \& Research, 33(2), pp. 261-304.

Dickey, David, and Wayne A. Fuller (1979), "Distribution of the Estimators for Autoregressive Time Series with a Unit Root", Journal of the American Statistical Association, 74, pp. 427-431.

24 The high level of stock prices in 2007 can be seen as "overshooting" rather than as "average benchmark". 
Elyasiani, Elyas, Iqbal Mansur, and Babatunde Odusami (2011), "Oil Price Shocks and Industry Stock Returns”, Energy Economics, (33), pp. 966-974.

Engle, Robert F. (1982), "Autoregressive Conditional Heteroskedasticity with Estimates of the Variance of U.K. Inflation", Econometrica, 50(4), pp. 987-1008.

Engle, Robert F., David M. Lilien, and Russel P. Robins (1987), "Estimating Time Varying Risk Premia in the Term Structure: The ARCH-M Model", Econometrica, 55(2), pp.391-407.

Fama, Eugene F., Lawrence Fisher, Michael C. Jensen, and Richard Roll (1969), "The Adjustment of Stock Prices to New Information", International Economic Review, (10), pp. 1-21.

Glosten, Lawrence R., Ravi Jagannathan, and David E. Runkle (1993), "On the Relation between the Expected Value and Volatility of the Nominal Excess Return on Stocks", The Journal of Finance, 48(5), pp. 1779-1801. Hammoudeh, Shawkat, and Yuan Yuan (2008), "Metal Volatility in Presence of Oil and Interest Rate Shocks", Energy Economics, (30), pp. 606-620. Hauser, Michael and Robert M. Kunst (1993), "Fractionally Integrated Models With ARCH Errors”, Forschungsbericht No.322, Institute for Advanced Studies.

Hauser, Michael, and Robert M. Kunst (1998), "Fractionally Integrated Models With ARCH Errors: With an Application to the Swiss 1-Month Euromarket Interest Rate", Review of Quantitative Finance and Accounting, 10, pp. 95-113.

Kollias, Christos, Stephanos Papadamou, and Costas Siriopoulos (2012), "Terrorism Induced Cross-Market Transmission of Shocks: A Case Study Using Intraday Data", Economics of Security Working Paper No. 66, EUSECON.

Kothari, S. P., and Jerold B. Warner (2007), "Econometrics of Event Studies", in Handbook of Corporate Finance, Espen Eckbo, ed., Vol. 1, pp.3-36, North Holland: Elsevier.

Kunst, Robert M. (1997), "Augmented ARCH Models for Financial Time Series: Stability Conditions and Empirical Evidence", Applied Financial Economics, 7(6), pp. 575-586.

Kunst, Robert M. (2003), "Testing for Relative Predictive Accuracy: A Critical Viewpoint”, Working Paper, University of Vienna.

Kwiatkowski, Denis, Peter C. B. Phillips, Peter Schmidt, and Yongcheol SHin (1992), "Testing the Null Hypothesis of Stationarity Against the Alternative of a Unit Root: How Sure Are We that Economic Time Series Have a Unit Root?", Journal of Econometrics, 54, pp. 159-178. 
Ljung, Greta M., and George E. P. Box (1978), "On a Measure of Lack of Fit in Time Series Models”, Biometrika, 66(2), pp. 265-270.

MacKinlay, A. Craig (1997), "Event Studies in Economics and Finance", Journal of Economic Literature, 35, pp. 13-39.

Phillips, Peter C. B., and Pierre Perron (1988), "Testing for a Unit Root in Time Series Regression”, Biometrika, 75(2), pp. 335-346.

Pynnönen, Seppo (2005), "On Regression Based Event Study", in Contributions to Accounting, Finance, and Management Science. Essays in Honor of Professor Timo Salmi, Erkkie K. Laitinen and Teija Latinen, eds., No. 143 of Acta Wasensia, pp. 327-354.

Schwarz, Gideon (1978), "Estimating the Dimension of a Model", Annals of Statistics, 6(2), pp. 461-464.

Stoica, Petre, Yngve Selén, and Jian li (2004), "On Information Criteria and the Generalized Likelihood Ratio Test of Model Order Selection”, IEEE Signal Processing Letters, 11(10), pp. 794-797.

Taylor, Stephen J. (1986), Modelling Financial Time Series, Chichester: John Wiley \& Sons.

Tsay, Ruey S. (1987), "Conditional Heteroscedastic Time Series Models”, Journal of the American Statistical Association, 82(398), pp. 590-604.

WeIss, ANdrew A. (1984), "ARMA Models with ARCH Errors", Journal of Time Series Analysis, 5(2), pp. 129-143.

Weiss, Andrew A. (1986), "Asymptotic Theory for ARCH Models: Estimation and Testing", Econometric Theory, 2(1), pp. 107-131.

Zakoian, Jean-Michel (1994), "Threshold Heteroskedastic Models", Journal of Economic Dynamics and Control, 18(5), pp.931-955.

\section{SUMMARY}

Additionally to the financial crisis causing a world recession, Liechtenstein's financial sector has been challenged by the so-called "Zumwinkel-Affair", when a whistle-blower sold data of hundreds of tax evaders to international tax authorities. This paper investigates the impact of this affair on the daily stock prices of banks from Liechtenstein. An unconventional augmented GARCH-model (labelled as "augmented amalGARCH"), which outperforms conventional models, is introduced and dynamically analyses various influences on risk and returns. Also, an event study framework is applied. The main finding beyond further conclusions is that the Zumwinkel-Affair had an (accumulating) effect on risk, but surprisingly no impact on average stock return could be detected. 